This article is licensed under the Creative Commons Attribution-NonCommercial 4.0 International License (CC BY-NC) (http://www.karger.com/Services/OpenAccessLicense). Usage and distribution for commercial purposes requires written permission.

\title{
Fibrosing Alopecia in a Pattern Distribution: A Case Report and Literature Review
}

\author{
Korn Triyangkulsri Ploychompoo Srisuwanwattana \\ Tueboon Sriphojanart Poonkiat Suchonwanit \\ Division of Dermatology, Department of Medicine, Faculty of Medicine, Ramathibodi \\ Hospital, Mahidol University, Bangkok, Thailand
}

\section{Keywords}

Alopecia $\cdot$ Cicatricial alopecia $\cdot$ Lichen planopilaris $\cdot$ Pattern hair loss $\cdot$ Scarring alopecia

\section{Abstract}

Fibrosing alopecia in a pattern distribution (FAPD) is a relatively new entity in the family of cicatricial alopecia. It has been categorized as a member of the lichen planopilaris (LPP) group due to its similarity in clinical and histopathological presentation. Nonetheless, the disease earns its own entity due to its lichenoid inflammation exclusively involving miniaturized hair and area of involvement mimicking pattern hair loss which differentiates itself from other types of LPP or pattern hair loss. Since its first introduction by Zinkernagel and Trüeb in 2000, there have been only few case reports and series of FAPD. We herein report a case of FAPD in a postmenopausal woman who had progressive hair loss over the course of 10 years. 


\section{Introduction}

Fibrosing alopecia in a pattern distribution (FAPD) is a form of lymphocytic cicatricial alopecia which affects the typical area of androgenetic alopecia (AGA) or female pattern hair loss (FPHL). Since its first introduction by Zinkernagel and Trüeb [1] in 2000, the condition has been recognized as a variant of lichen planopilaris (LPP) due to its similarity in clinical and histopathological characteristics $[1,2]$.

\section{Case Report}

A 58-year-old female presented to the dermatology clinic with a history of progressive hair loss over 10 years. The hair loss began from the central scalp and gradually spread centrifugally (Fig. 1). She also complained of burning sensation of the affected area of the scalp. The patient denied previous illness before the onset of alopecia. There was also no history of significant weight loss or family history of pattern hair loss. She had no underlying disease and was not taking any medication or supplement during that time.

Scalp examination revealed diffuse alopecia predominantly on the vertex, frontal, and parietal area. Perifollicular scale, mild perifollicular erythema, and follicular dropout were generally observed within the alopecic area. Trichoscopic examination showed diversity of hair shaft diameter, focal atrichia, whitish areas, mild interfollicular erythema, and arborizing blood vessels (Fig. 2). Physical examination was unremarkable for other areas and systems. Lesional scalp biopsy was done. The specimen showed miniaturized hair follicle and dense inflammatory cell infiltrate of lymphocytes around the upper portion of hair follicle. There was no interface dermatitis of the interfollicular epidermis (Fig. 3).

She initially received desoximetasone cream to be applied to the affected area once daily and hydroxychloroquine $200 \mathrm{mg} /$ day. Hair loss and burning sensation of the scalp were halted after 1 month of treatment. Subsequently, 3\% minoxidil lotion, to be applied twice daily, and finasteride $2.5 \mathrm{mg} /$ day were added to the treatment. Hair growth was noted after 2 months and inflammation subsided. The absence of perifollicular scales and interfollicular erythema was noted after 5 months of treatment. These improvements were maintained throughout the 1-year follow-up period.

\section{Discussion}

AGA and FPHL are very common causes of non-scarring alopecia worldwide, with a prevalence of around $30 \%$ in males over 30 years and postmenopausal females, and the prevalence increases further to up to $80 \%$ by the age of 70 years [3-6]. The diagnosis of this pattern hair loss is usually made based on clinical presentation. However, the introduction of FAPD raises the question whether these patients would reveal signs of cicatricial alopecia and some of these patients would, in fact, have FAPD.

Cases of FAPD have been reported in many regions worldwide [1,7-11]. The distinctive histopathologic features of FAPD were miniaturization of hair follicles with prominent lichenoid inflammation and destruction of the follicular basilar epithelium in the isthmus and 
infundibular region of the follicle. Interface dermatitis in interfollicular epidermis was rarely found in FAPD. These findings overlap between AGA and LPP [1]. Nevertheless, some had addressed FAPD as a subset of LPP due to its cicatricial alopecic findings and similar histopathology $[2,9]$. Naturally, the differential diagnosis of FAPD are AGA/FPHL and members of cicatricial alopecia groups such as classic LPP or central centrifugal scarring alopecia which usually can be differentiated through clinical pattern and histopathology (Table 1).

The etiology and pathogenesis of FAPD have yet to be elucidated. Nevertheless, the efficacy of antiandrogen therapy, in stabilizing the progression of hair loss and decreasing the scalp inflammation in some cases, suggested that androgen may play a role in the development of the inflammatory process of the scalp [1]. Further studies are warranted to unravel the underlying factors responsible for these inflamed androgenetic hair follicles.

In conclusion, we present a case of FAPD in a postmenopausal woman who had progressive hair loss over the course of 10 years. Interestingly, the onset of hair loss in our patient was relatively lengthy and yet there were moderate responses to the treatment. Given the irreversible nature of later stage of cicatricial alopecia, these findings raise the possibility in which the patient actually had FPHL and later developed FAPD or FAPD is, in fact, a late manifestation of some cases of FPHL.

\section{Statement of Ethics}

Informed consent was obtained from the patient for any materials used in the manuscript. This case report was conducted ethically in accordance with the World Medical Association Declaration of Helsinki.

\section{Disclosure Statement}

The authors have no conflicts of interest to declare.

\section{Funding Sources}

The authors did not receive any funding.

\section{References}

1 Zinkernagel MS, Trüeb RM. Fibrosing alopecia in a pattern distribution: patterned lichen planopilaris or androgenetic alopecia with a lichenoid tissue reaction pattern? Arch Dermatol. 2000 Feb;136(2):205-11.

2 Sperling LC, Solomon AR, Whiting DA. A new look at scarring alopecia. Arch Dermatol. 2000 Feb;136(2):235-42.

3 Otberg N, Finner AM, Shapiro J. Androgenetic alopecia. Endocrinol Metab Clin North Am. 2007 Jun;36(2):379-98. 
4 Suchonwanit P, Srisuwanwattana P, Chalermroj N, Khunkhet S. A randomized, double-blind controlled study of the efficacy and safety of topical solution of $0.25 \%$ finasteride admixed with $3 \%$ minoxidil vs. $3 \%$ minoxidil solution in the treatment of male androgenetic alopecia. J Eur Acad Dermatol Venereol. 2018 Dec;32(12):2257-63.

5 Ioannides D, Lazaridou E. Female pattern hair loss. Curr Probl Dermatol. 2015;47:45-54

6 Suchonwanit P, Iamsumang W, Rojhirunsakool S. Efficacy of Topical Combination of $0.25 \%$ Finasteride and 3\% Minoxidil Versus 3\% Minoxidil Solution in Female Pattern Hair Loss: A Randomized, Double-Blind, Controlled Study. Am J Clin Dermatol. 2019 Feb;20(1):147-53.

7 Chiu HY, Lin SJ. Fibrosing alopecia in a pattern distribution. J Eur Acad Dermatol Venereol. 2010 Sep;24(9):1113-4.

8 Fergie B, Khaira G, Howard V, de Zwaan S. Diffuse scarring alopecia in a female pattern hair loss distribution. Australas J Dermatol. 2018 Feb;59(1):e43-6.

9 Olsen EA. Female pattern hair loss and its relationship to permanent/cicatricial alopecia: a new perspective. J Investig Dermatol Symp Proc. 2005 Dec;10(3):217-21.

10 Amato L, Chiarini C, Berti S, Bruscino P, Fabbri P. Case study: fibrosing alopecia in a pattern distribution localized on alopecia androgenetica areas and unaffected scalp. Skinmed. 2004 Nov-Dec;3(6):353-5.

11 Mardones F, Hott K, Martinez MC. Clinical study of fibrosing alopecia in a pattern distribution in a Latin American population. Int J Dermatol. 2018 Feb;57(2):e12-4.

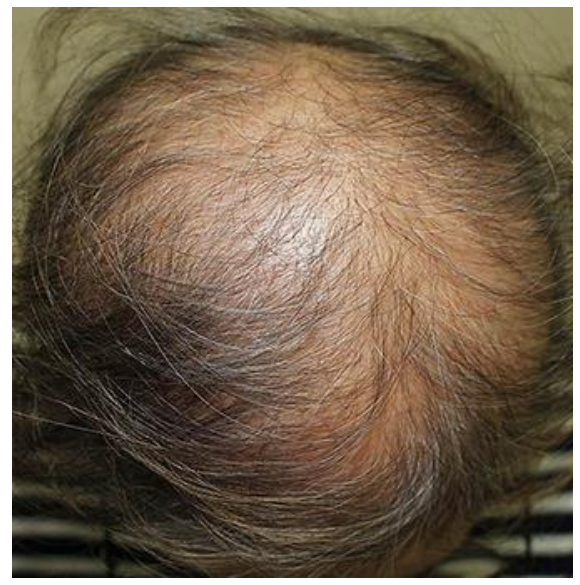

Fig. 1. Diffuse alopecia distributed predominantly on the vertex, frontal, and parietal area. 


\section{Case Reports in Dermatology}

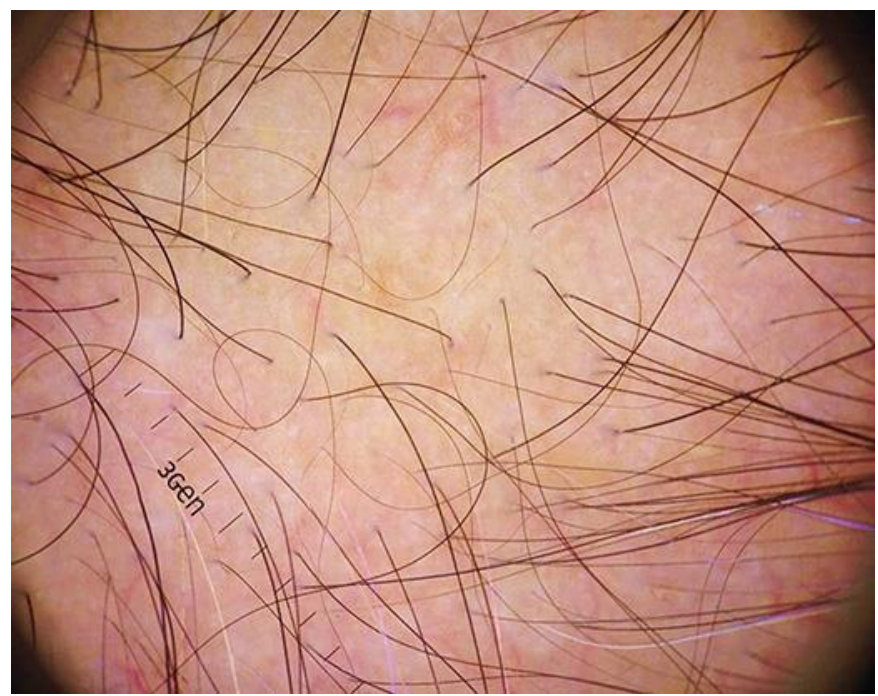

Fig. 2. Trichoscopy shows diversity of hair shaft diameter, focal atrichia, honeycomb pigmentation, whitish spots and patches, mild interfollicular erythema, and arborizing blood vessels (original magnification $\times 20$ ).

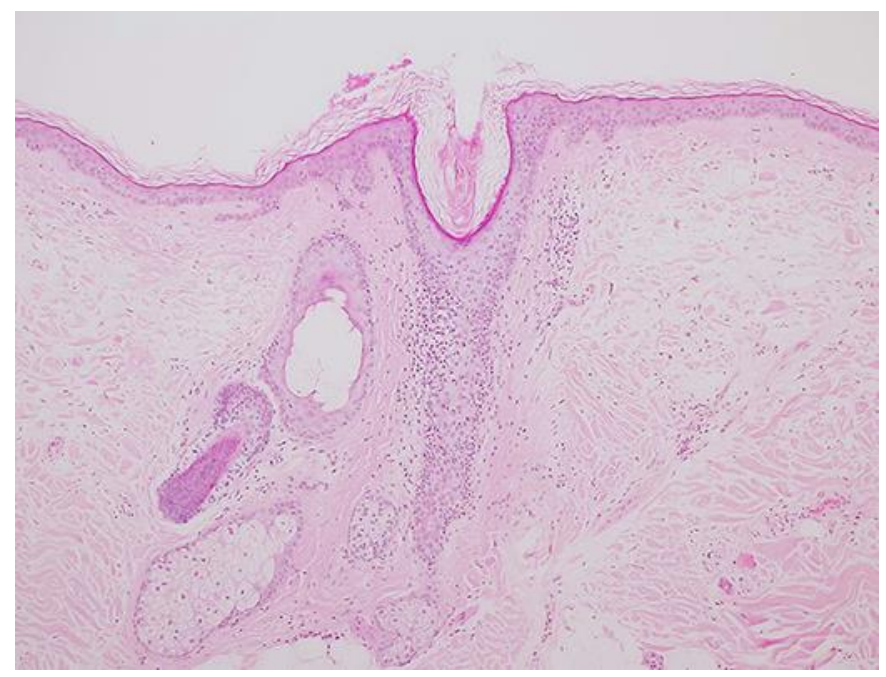

Fig. 3. Histopathological examination shows miniaturized hair follicle and dense perifollicular lymphocytic infiltration around the upper portion of hair follicle. No interface dermatitis of interfollicular epidermis (hematoxylin-eosin, original magnification $\times 40$ ). 


\section{Case Reports in Dermatology}

Table 1. Characteristics of differential diagnosis of fibrosing alopecia in a pattern distribution

\begin{tabular}{|c|c|c|c|c|}
\hline & AGA/FPHL & FAPD & Classic LPP & CCCA \\
\hline Type & Non-scarring & Scarring & Scarring & Scarring \\
\hline $\begin{array}{l}\text { Clinical } \\
\text { presentation }\end{array}$ & $\begin{array}{l}\text { Pattern distributed } \\
\text { alopecia } \\
\text { AGA: bitemporal and } \\
\text { crown } \\
\text { FPHL: crown and } \\
\text { vertex, usually spare } \\
\text { frontal hair line }\end{array}$ & $\begin{array}{l}\text { Pattern distributed } \\
\text { alopecia same as } \\
\text { AGA/FPHL }\end{array}$ & $\begin{array}{l}\text { Highly variable but } \\
\text { commonly presented } \\
\text { with scattered foci of } \\
\text { partial hair loss }\end{array}$ & $\begin{array}{l}\text { Crown or vertex } \\
\text { of the scalp, } \\
\text { expanding to } \\
\text { periphery }\end{array}$ \\
\hline Histopathology & $\begin{array}{l}\text { - Miniaturized } \\
\text { hair follicle } \\
\text { - No interface } \\
\text { dermatitis }\end{array}$ & $\begin{array}{l}\text { - Miniaturized hair follicle } \\
\text { - Lichenoid inflammation } \\
\text { selectively targeting } \\
\text { isthmus and infundibular } \\
\text { region of miniaturized } \\
\text { hair follicle } \\
\text { - No interface dermatitis }\end{array}$ & $\begin{array}{l}\text { - Lichenoid inflammation } \\
\text { predominantly targeting } \\
\text { isthmus and infundibular } \\
\text { region of terminal hair } \\
\text { follicle } \\
\text { - Interface dermatitis in } \\
\text { interfollicular epidermis }\end{array}$ & $\begin{array}{l}\text { - Premature } \\
\text { desquamation of } \\
\text { inner root sheath } \\
\text { - No interface } \\
\text { dermatitis }\end{array}$ \\
\hline
\end{tabular}

AGA, androgenetic alopecia; FPHL, female pattern hair loss; FAPD, fibrosing alopecia in a pattern distribution; LPP, lichen planopilaris; CCCA, central centrifugal cicatricial alopecia.

Triyangkulsri et al.: Fibrosing Alopecia in a Pattern Distribution: A Case Report and Literature Review 